\title{
EXPLORING PATHWAYS TO NEGATE SAFETY CONCERNS AND IMPROVE PUBLIC ACCEPTANCE OF ALTERNATIVE FUELLED ELECTRIC VEHICLES
}

\author{
HANLIN LI, RUTH WELSH \& ANDREW MORRIS \\ Transportation Safety Research Group, Loughborough University, UK
}

\begin{abstract}
Restricted emission regulations force the transportation sector to seek a better vehicle fuel solution, and the uptake of Electric Vehicle is to be encouraged because it has no exhaust emission. Previous literature had shown that range freedom and cost were the main barriers and safety aspects were often considered as technological issues. Recent research indicates that early adopters of innovative EVs do have concerns about safety issues although it was not on top of the list. However, research into the public perception of alternative fuelled EVs in terms of safety has been limited to date. In this paper, a quantitative study is undertaken to investigate the public safety concern of three types of vehicle powertrain: the internal combustion engine, the hybrid electric and the solely electric vehicle. The survey consisted of two identical sets of questionnaires (one was in English, and another in Chinese) to collect data from people with different cultural background. It was expected that this would provide a reasonable number of responses to reflect the public. This study indicates that the main safety concerns are associated with the level of vehicle knowledge and the power supply components despite the powertrain type. The high awareness of mechanical failure is only evident in the conventional fuel powertrain and gradually reduced when moving towards solely electric powertrain to compensate for the rise of electrical failure awareness. It also indicates that the awareness of the specifics of hydrogen fuel cell vehicles is not widespread amongst the public as almost all the participants considered that the electric vehicle is powered by batteries only. As a result, this paper suggests that there is a need to educate the drivers with the desired knowledge while simply driving the vehicle could potentially be an effective way to improve public acceptance of any alternative fuel vehicle.
\end{abstract}

Keywords: safety concerns, public acceptance, alternative fuel, electric vehicle.

\section{INTRODUCTION}

Carbon dioxide $\left(\mathrm{CO}_{2}\right)$ and other Green House Gases (GHG) are the main causes of the climate changes, and exhaust emissions from vehicles account towards a significant contribution to global air pollution and eventually global warming. Nowadays, one of driving forces for the development of innovative and sustainable vehicles is the restricted emission standards, such as the movement form Euro 1 (1992) to Euro 6 (2017) [1]. Under this situation, the Electric Vehicle (EV) has been widely accepted as the potential "green" solution as it has either reduced exhaust emission (hybrid) or no exhaust emission (solely electric). Previous studies had shown that range freedom due to recharge capability and cost of owning an EV were the main barriers for those who wanted to switch to an alternative fuelled electric vehicle [2], [3], and vehicle safety was often considered as a technological issue. Recently, Hardman et al. [4] reported that early adopters of innovative EVs do have concerns about safety aspects although they were not on top of the list. However, research into the public perception of alternative fuelled EVs in terms of safety has been limited to date.

The aim of this paper to present a baseline for the understanding of the safety concerns from driver's point of view and to propose potential solutions to negate these concerns as well as improving public acceptance of alternative fuelled electric vehicles. 


\section{METHODS}

In this study, a questionnaire survey was developed and distributed to collect data with respect to the safety concerns of three types of vehicle powertrains, namely: 1) the conventional Internal Combustion (IC) engine vehicle powertrain which uses either petrol or diesel fuel; 2) the hybrid electric vehicle powertrain which combines the IC engine and an electrical motor to generate additional power; and 3) the solely electric vehicle which utilizes generated electricity to drive the wheel.

In addition, the questionnaire had two identical versions. One was in English and another in Chinese. The questionnaire was distributed in Chinese language since this country has more than 1/3 of the total electric vehicles in the world [5] and English is not an essential language for Chinese drivers. The Chinese version was developed to collect those drivers' opinions whilst minimising any uncertainties due to misunderstanding. The data was then analysed using Pareto analysis to identify the most significant aspects to address, thereby making the development effort more effective.

\section{RESULTS AND DISCUSSION}

The survey period was 3 weeks, and a total of 96 responses were collected. Within these responses, 4 of them were from a non-driver and therefore were considered as other roadusers. $29.2 \%(n=28)$ of the total responses came from China.

\subsection{General participants purchase concerns}

Fig. 1 below shows the awareness of various concerns when considering the purchase of a car, from high to low. It was not surprising that "Price" was the most significant factor.

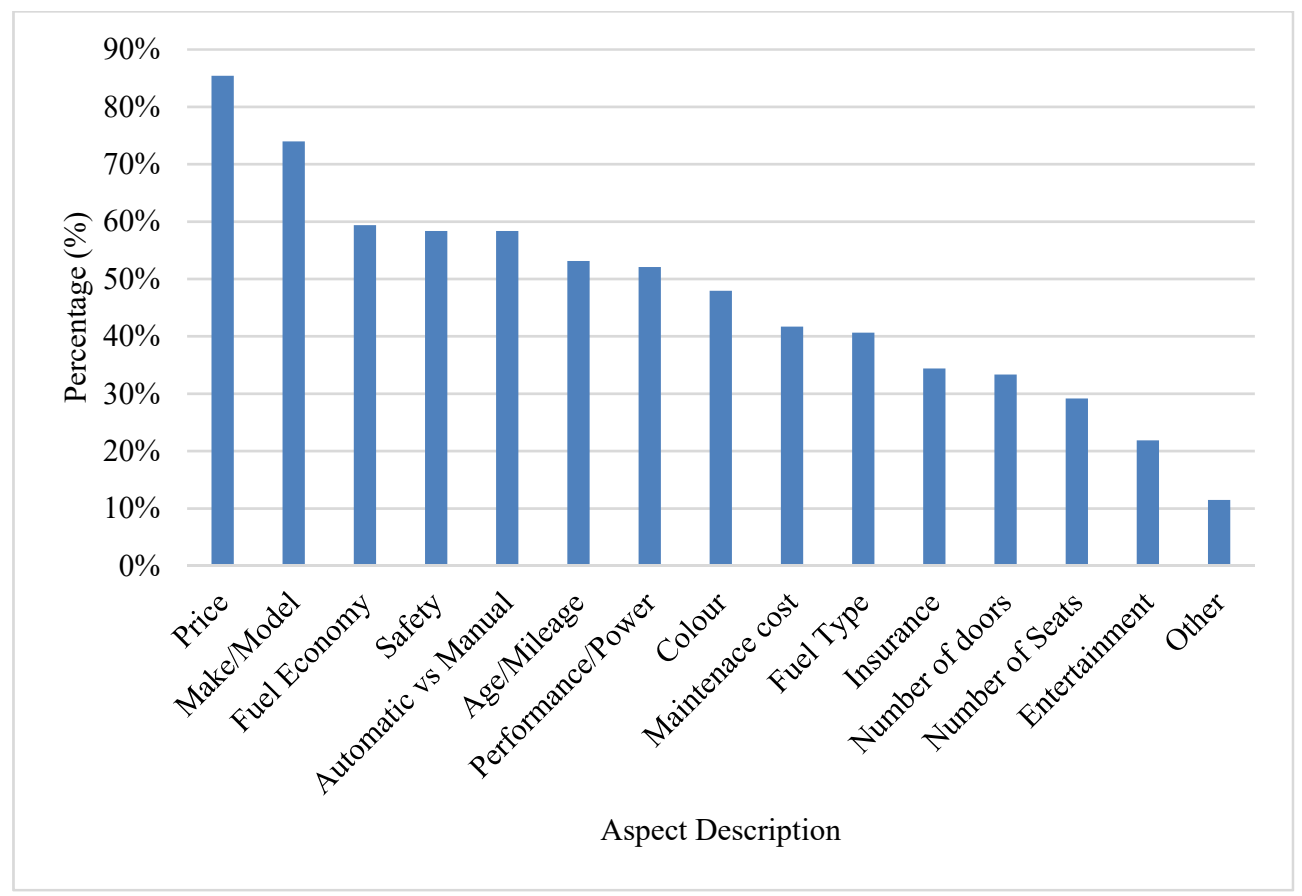

Figure 1: Percentage of participants that concern each individual aspect. 
However, $74 \%(n=71)$ of the total participants considered that the "Make/Model" of the car was also important. This is because most participants were not so familiar with automotive design (as indicated in the Questionnaire) and therefore had limited knowledge regarding vehicles in general. Overall, they therefore relied on brand reputation to judge the quality of the vehicles. Regarding general vehicle safety concern, $58.3 \%(n=56)$ of the total participants concerned safety and $57.1 \%(n=32)$ of participants considered purchasing either German brands or brands that use German technologies (e.g. Volvo for safety reason). This shows that people tend to trust the brand reputation in terms of safety issues. Based on the past history of the conventional IC engine and the current Tesla battery electric vehicle, it could be predicted that the safety factor will be much more prominent as a factor amongst the public and once the EV technologies have been fully commercialised.

\subsection{Specific safety concerns regarding various vehicle powertrains}

In this section, the safety concerns are presented regarding the three types of vehicle powertrain: the IC engine, the hybrid and the solely electric. A 2D bar chart was produced using Pareto analysis to identify criteria that are of most important to the safety concern of each type of powertrain (as shown in Fig. 2). In general, the high awareness of mechanical failure was only evident in the conventional fuel powertrain and gradually reduced when moving towards solely electric powertrain to compensate for the rise of electrical failure awareness. However, neither of these two factors are major concerns.

\subsubsection{Knowledge-based factors}

Fig. 2 below indicates that it was difficult for the majority of participants to come up with the specific safety issues as the "None" factor showed a higher concerned frequency. In case of the conventional IC engine powertrain, a proportion of these participants consider that this mature technology is safe as this has been a well-established technology for serval decades, and therefore, there is no specific safety issues that should be considered. However, these participants ignored the fact that even mature technologies have potential safety risks, such as fuel leakage and tank explosions. In the case of hybrid and solely electric vehicles, the participants indicated that they didn't understand the technology as well as the car itself, and

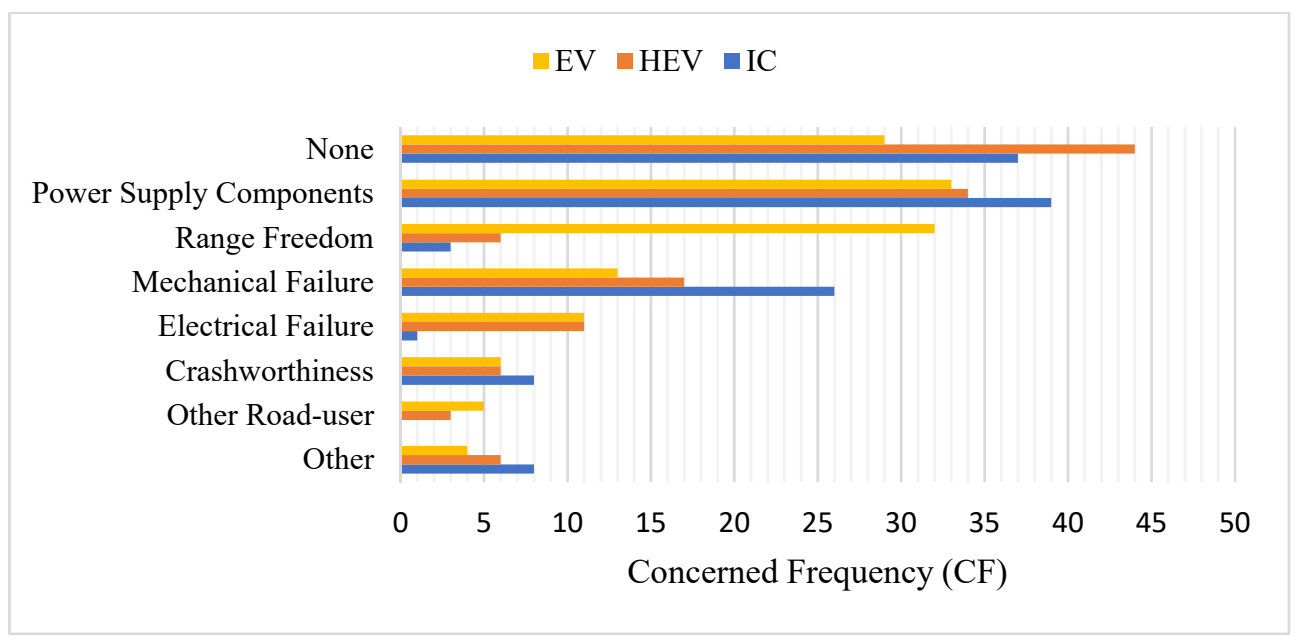

Figure 2: The concerned frequency of each individual safety issue. 
the lack of basic fix skills and knowledge of the innovative electric technology also makes it harder to indicate any specific safety issues. As a result, the lack of knowledge of the innovative technologies leads to a lack of confidence.

In addition, the "Range Freedom" factor is extremely higher for the solely electric vehicle $(\mathrm{CF}=32)$ than for the hybrid $(\mathrm{CF}=6)$ and IC engine vehicle $(\mathrm{CF}=3)$. This is because this factor considers the risk of out of charge/fuel and the ease of refuelling availability. The results show that participants are mainly afraid of running out of charge for the electric vehicle during their journey. Although the current EVs meet the technical daily driving distance requirement already and home charging facilities together with on-site charging ports are widely available, the freedom of drive is still affecting the drivers mentally. Participant 71 specifically commented that "Obsessive-Compulsive Disorder (OCD) cannot tolerate the lower electricity charge". As a result, the driving freedom is not just a problem of infrastructure only but is also a psychological issue to some extent.

\subsubsection{Power supply components}

Fig. 2 also indicates that power supply components attract the second most awareness. In this section, these power supply components are discussed in detail with respect to each individual powertrain. The safety concerns are considered according to three different categories. The first category, namely "Explosion/Fire", represents the concerns in terms of fuel tank explosion or fire and battery fire specifically. The remaining phenomena of battery failure are presented in the second category "Battery Failure", such as battery deformation, leakage, state-of-health etc. The third category represents the concerns regarding fuel leakage and hazards exhaust gases. The percentage of concerned categories for each type of powertrain is presented in Fig. 3.

In case of the conventional IC engine, $1 / 3$ of the concerned safety is related to the fuel tank explosion and fire, and the remaining $2 / 3$ of concerns are related to fuel leakage and hazard gases. However, the failures associated with batteries contained in IC powertrain are neglected by all participants. In case of a hybrid electric vehicle, the concerned frequency of explosion and fire is increased to $47.1 \%(\mathrm{CF}=16)$. This is because awareness of potential

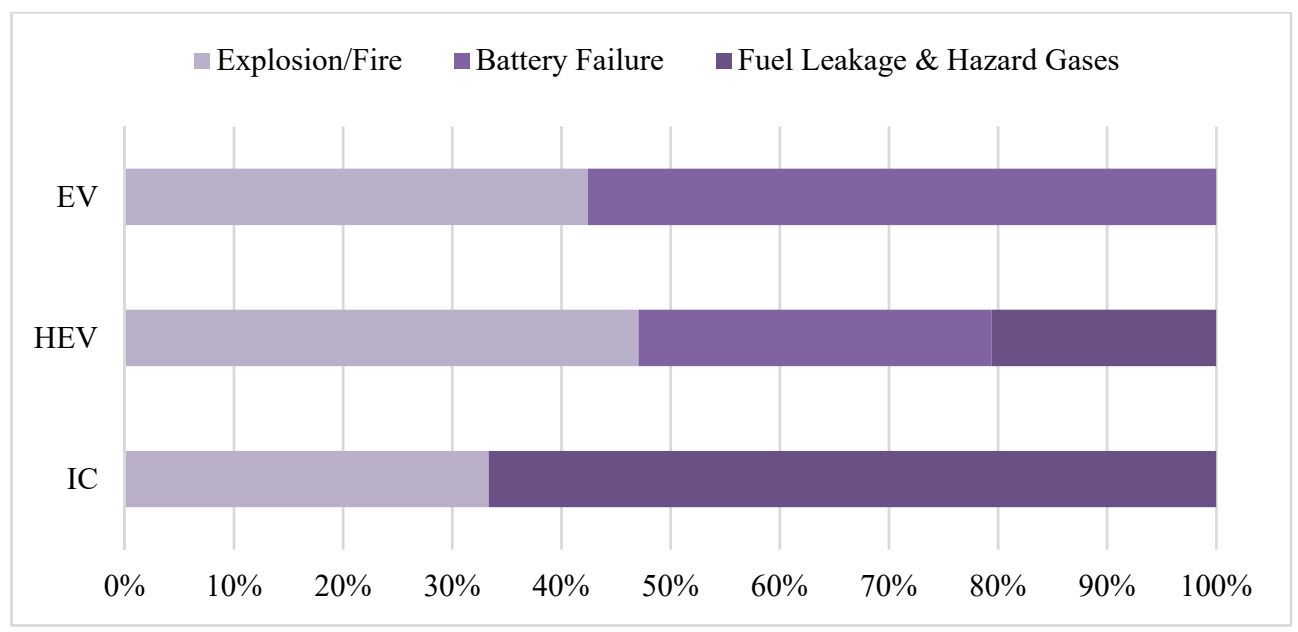

Figure 3: Percentage of various power supply components safety concerns. 
battery fire is increased due to recent Tesla battery fire news. Also, the concerned frequency of fuel aspect issues is reduced to $20.6 \%(\mathrm{CF}=7)$ due to the fact that battery failure concern is emerging. Moving towards the solely electric vehicles, the concerned frequency of battery fire and explosion is $42.4 \%(\mathrm{CF}=14)$, and the battery failure concerned frequency is $57.6 \%$ $(\mathrm{CF}=19)$. As a result, it would be more effective to negate the safety concern by providing the driver with information of power source container (the battery in this case) than the entire transmission powertrain information.

\subsubsection{Hydrogen fuel vehicle perception}

While formulating the questionnaire, the questions are carefully stated in such a way that the term battery and hydrogen were not posed. This is because people tend to lock down to a particular fuel type in their mind (i.e. battery or hydrogen) when they are asked to assess the safety concern with respect to that particular fuel type. Therefore, the answers from this survey can also represent the public awareness level of the hydrogen fuel vehicle. The result indicates that the awareness of the specifics of hydrogen fuel cell vehicles is not widespread amongst the public as almost all the participants considered that the electric vehicle is powered by batteries only.

In addition, the hydrogen fuel vehicle consists of a fuel tank to store the hydrogen and pass it to the fuel cell to generate electricity for the motor that powers the wheel. By integrating the conclusion from Section 3.2.2, it can be proposed that providing the state information regarding the hydrogen tank and the fuel cell to the driver is an effective way to negate the safety concern of hydrogen technology, and hence effectively increase the public acceptance as well.

\section{CONCLUSION}

In this paper, a quantitative survey was developed to investigate the public safety concerns of three types of vehicle powertrain: the internal combustion engine, the hybrid electric and the solely electric vehicle. In general, it can be predicted that safety concern will raise its awareness as the technologies move towards their maturity. The lack of appropriate knowledge of the innovative technologies is a key issue that causes lack of confidence and public acceptance.

Also, the survey results indicate that driving freedom is nowadays not just a problem of infrastructure only but is gradually becoming a psychological issue as well. It could be more effective to negate the safety concern by providing the driver with information on power source container, the entire transmission powertrain and any other components.

Furthermore, this paper suggests that there is a need to educate the drivers with the desired knowledge whilst simply driving the vehicle could potentially be an effective way to improve public acceptance of any alternative fuel vehicle. Regarding the increasing availability of hydrogen fuel cell vehicles, a potential pathway to negate the safety concerns and improve public acceptance is proposed in terms of desired information of both vehicles and power supply components.

Last but not least, the survey will be expanded to a longer period for additional responses, and a structural interview will be constructed as the next stage to understand the in-depth knowledge required.

\section{ACKNOWLEDGEMENT}

This research is funded by the Engineering and Physical Science Research Council (EPSRC) through the Centre for Doctoral Training in Fuel Cells and Their Fuels at Loughborough University. 


\section{REFERENCES}

[1] The AA, Limits to improve air quality and health, AA website, Online. www.theaa.com/driving-advice/fuels-environment/euro-emissions-standards. Accessed on: 5 Aug. 2018.

[2] Campbell, A.R., Ryley, T. \& Thring, R., Identifying the early adopters of alternative fuel vehicles: A case study of Birmingham, United Kingdom. Transportation Research Part A: Policy and Practice, 46(8), pp. 1318-1327, 2012. DOI: $10.1016 /$ j.tra.2012.05.004.

[3] Hardman, S., Chandan, A., Shiu, E. \& Steinberger-Wilckens, R., Consumer attitudes to fuel cell vehicles post trial in the United Kingdom. International Journal of Hydrogen Energy, 41(15), pp. 6171-6179, 2016. DOI: 10.1016/j.ijhydene.2016.02.067.

[4] Hardman, S., Shiu, E., Steinberger-Wilckens, R. \& Turrentine, T., Barriers to the adoption of fuel cell vehicles: A qualitative investigation into early adopters attitudes. Transportation Research Part A: Policy and Practice, 95, pp. 166-182, 2017. DOI: 10.1016/j.tra.2016.11.012.

[5] International Energy Agengy, "Global EV Outlook 2018," 2018. 